\title{
ANTIARRHYTHMIC EFFECT OF OXPRENOLOL ON HALOTHANE-EPINEPHRINE AND CORONARY LIGATION INDUCED VENTRICULAR ARRHYTHMIAS IN BEAGLE DOGS
}

\author{
Keitaro HASHIMOTO, Tokumasa TSUKADA, Hiroto MATSUDA, \\ Issei MATSUBARA and Shoichi IMAI \\ Department of Pharmacology, Niigata University, School of Medicine, \\ Niigata 951, Japan
}

Accepted January 23, 1978

\begin{abstract}
Antiarrhythmic effects of oxprenolol, a $\beta$-blocker, were studied quantitatively on arrhythmias produced by epinephrine during halothane anesthesia and by two-stage coronary ligation, and were compared to those of other $\beta$-blockers, propranolol and $\mathrm{Kö} 1400$, which have been already reported. Though oxprenolol has potent $\beta$-blocking activity, the antiarrhythmic effect on halothane-epinephrine arrhythmia was significantly weaker than those of propranolol and Kö 1400. The effective dose of oxprenolol was $60 \perp 18 \mu \mathrm{g} / \mathrm{kg}$ (mean $\perp$ S.E., $N=6$ ), which is in the range of the so-called $\beta$-adrenergic blocking dose. The weaker antiarrhythmic effect of oxprenolol as compared to propranolol and $\mathrm{Kö} 1400$ is probably due to the intrinsic positive chronotropic effect, which is most clearly observed in oxprenolol as compared to the other two drugs. As for two-stage coronary ligation arrhythmia, oxprenolol suppressed only that observed 48 hours after coronary ligation using higher doses (5 to $10 \mathrm{mg} / \mathrm{kg}$ ). Other $\beta$-blockers also showed similar effects. Because of the high doses necessary for the antiarrhythmic effects on the coronary ligation arrhythmia, the mechanism for suppressing the arrhythnia is probably due to the local anesthetic action of the $\beta$-blockers.
\end{abstract}

$\beta$-Adrenergic blocking agents ( $\beta$-blockers) are known to have antiarrhythmic effects, some of which have been shown to be unrelated to $\beta$-blocking effects (1-3). Nonspecific effects of $\beta$-blockers responsible for suppression of arrhythmias include the so-called quinidine-like effect which is often called the local anesthetic or direct cardiodepressant effect. Quantitative comparison of $\beta$-blocking effects and the other effects has already been conducted, but the antiarrhythmic effect has not been studied quantitatively enough to be compared with other effects. This situation has made it difficult to pinpoint an antiarrhythmic mechanism or mechanisms of the $\beta$-blockers on a given arrhythmia.

Recently, Matsubara et al. quantitatively compared the antiarrhythmic effect of a new $\beta$-blocker, Kö 1400, with propranolol in halothane-epinephrine and coronary ligation ventricular arrhythmias in beagle dogs along with other experimental arrhythmias (4). The present paper deals with 1) the quantitative methods for evaluating antiarrhythmic activity on halothane-epinephrine and coronary ligation arrhythmias and 2) antiarrhythmic effects of oxprenolol in comparison with $\mathrm{Kö} 1400$ and propranolol. The three $\beta$-blockers were chosen for their different actions. Their characteristics are as follows: oxprenolol has $\beta$-blocking activity slightly stronger than propranolol with positive chronotropic activity 
and weak local anesthetic activity; Kö 1400 has strong $\beta$-blocking activity with weak positive chronotropic and local anesthetic activity; propranolol has no positive effect but strong local anesthetic activity.

\section{MATERIALS AND METHODS}

Expcriments were performed using beagle dogs of either sex, weighing 9 to $12 \mathrm{~kg}$.

\section{1) Halothane-epinephrine arrhythmia}

The methods for the production of ventricular arrhythmia by intravenous injection of epinephrine during halothane anesthesia were similar to those reported previously by Hashimoto and Hashimoto (5). Briefly, the animal was anesthetized with sodium thiopental, $30 \mathrm{mg} / \mathrm{kg}$ i.v., and after intubation, $1.5 \%$ halothane was introduced. Halothane was vaporized with $95 \% \mathrm{O}_{2}-5 \% \mathrm{CO}_{2}$ using a calibrated vaporizer (Fluotec 3 ) and was delivered using a constant volume respirator (Takashima). The tidal volume of the respirator was $10 \mathrm{ml} / \mathrm{kg}+50 \mathrm{ml}$ of the dead space of the tubings, and the respiratory rate, $20 / \mathrm{min}$. During the first 30 minutes for stabilizing halothane effects, the femoral artery and vein wcre dissected aseptically in order to measure the systemic blood pressure and to infuse drugs intravenously. Epinephrine was dissolved in $20 \mathrm{ml}$ saline and injected from the cannulae into the femoral vein in 50 seconds. The dose of epinephrine was increased from $1 \not \mathrm{g} / \mathrm{kg}$ to $2,2.5,3,4$ and $6 / \mathrm{g} / \mathrm{kg}$ until ventricular tachycardia of multifocal origin and of over 30 seconds duration was produced. Ten minutes were allowed for the recovery from the epinephrine effect. The arrhythmic dose of cpinephrine was used at least twice in order to confirm that the arrhythmia thus produced was reproducible. Then $\beta$-blockers were injected. The initial dose of the $\beta$-blockers was usually chosen as the same $w / v$ dose as that of the arrhythmic dose of epinephrine. Five minutes after the initial injection of $\beta$-blocker, epinephrine was injected. Ten minutes later (total time lapse 15 minutes), $\beta$-blocker was again administered in larger doses and again followed by epinephrine. The increase was in the order of $2 \times$, $2 \times, 5 \times, 10 \times$ and so on of the $w / v$ dose of epinephrine: thus the cumulative dose was $3 \times$, $5 \times, 10 \times, 20 \times$, the epinephrine dose. This pattern was repeated until the ventricular tachycardia was suppressed. The antiarrhythmic effects of oxprenolol were expressed by the minimum antiarrhythmic ratio, i.e., the molar effective antiarrhythmic dose of oxprenolol/ the molar arrhythmic dose of epinephrine. In some dogs the extrasystoles could not be abolished by increasing the dose of oxprenolol even after successful suppression of multifocal tachycardia. In those cases, disappearance of burst of arrhythmia was judged as suppressive.

Experiments using Kö 1400 and propranolol were performed in 6 dogs and the data were added to those reported by us (4) in order that statistical comparison of oxprenolol, Kö 1400 and propranolol could be made.

\section{2) Coronary ligation arrhythnia}

Beagle dogs used for the study of halothane-epinephrine arrhythmias (Section 1) were allowed to recover for 1 month before being used for this study. Dogs were anesthetized initially with sodium thiopental, $30 \mathrm{mg} / \mathrm{kg}$, i.v., followed by $1.5 \%$ halothane anesthesia. 
The heart was exposed aseptically through a left thoracotony in the 5th intercostal space. The pericardium was incised to expose the anterior descending coronary artery, and a twostage coronary ligation was performed according to the method described by Harris (6). The animals were studied 24 hours and 48 hours after operation under unanesthetized conditions. Pharmacokinetic data suggest that almost all the drugs given 24 hours after the coronary ligation will be eliminated from plasma within the next 24 hours (7).

Oxprenolol was injected within 30 seconds through a catheter placed in the brachiocephalic vein and lead II of the ECG was continuously monitored. Analysis of ECG was performed as previously described (8). The arrhythmic ratio was determined (as the frequency of idioventricular beats divided by the total heart rate) before and after intravenous oxprenolol.

An intravenous injection of oxprenolol was made every 20 minutes until either the arrhythmia was suppressed or the dose reached $5 \mathrm{mg} / \mathrm{kg}$ for the $24 \mathrm{th}$ hour and $10 \mathrm{mg} / \mathrm{kg}$ for the 48th hour experiments. Ten $\mathrm{mg} / \mathrm{kg}$ of oxprenolol was lethal for two dogs on the first post-operative day. Previously we reported that the use of Kö 1400 and propranolol, in doses of $10 \mathrm{mg} / \mathrm{kg}$, resulted in the death, for each drug, of one dog (4). The initial doses of oxprenolol were $0.1 \mathrm{mg} / \mathrm{kg} ; 0.4,0.5$ and $2 \mathrm{mg} / \mathrm{kg}$ was added every 20 minutes. The antiarrhythmic dose was expressed in the total cumulative dose. One experiment using propranolol was performed in order to add data to that of our previous paper (4).

The antiarrhythmic activity was evaluated by two methods as previously described (8). First, the arrhythmic ratio was determined at the maximal dosage of the drug for each animal. The effects were graded as follows, 1) almost no effect, i.e. $0.50 \%$ reduction of the arrhythmic ratio, 2) 50-90\% reduction and 3) a greater than $90 \%$ reduction of the arrhythmic ratio for at least 1 min. In the other methods, the maximal changes in the total heart rate and the sinus beats were determined for each dose of the drug, and dose-effect curves were constructed.

Drugs used were dl-oxprenolol $\mathrm{HCl}$, dl-Kö $1400 \mathrm{HCl}$, dl-propranolol $\mathrm{HCl}$ and 1epinephrine $\mathrm{HCl}$.

Statistical comparisons were made using Student's t-test.

\section{RESULTS}

\section{Halothane-epinephrine arrhythmias}

In the first 30 minutes of $1.5 \%$ halothane anesthesia, the blood pressure and the heart rate reached a steady state, the average values of 12 dogs were $116 \div 7 \mathrm{mmHg}$ and $79+8$ $\mathrm{mmHg}$ for the systolic and diastolic blood pressure respectively, and 143.19 beats/min for the heart rate (mean $\_$S.E.). During the control period for determining the arrhythmic dose of epinephrine, the blood pressure and the heart rate returned to the same value $10 \mathrm{~min}$ after the intravenous injection of epinephrine. Arrhythmias of at least over 30 seconds duration and of multifocal origin as shown in Fig. 1 were produced by an average dose of epinephrine, $2.6 \_0.3 \mathrm{~kg} / \mathrm{kg}(\mathrm{n}=12)$. The minimum antiarrhythmic ratio, i.e., effective antiarrhythmic dose of oxprenolol/arrhythmic dose of epinephrine, was obtained by com- 


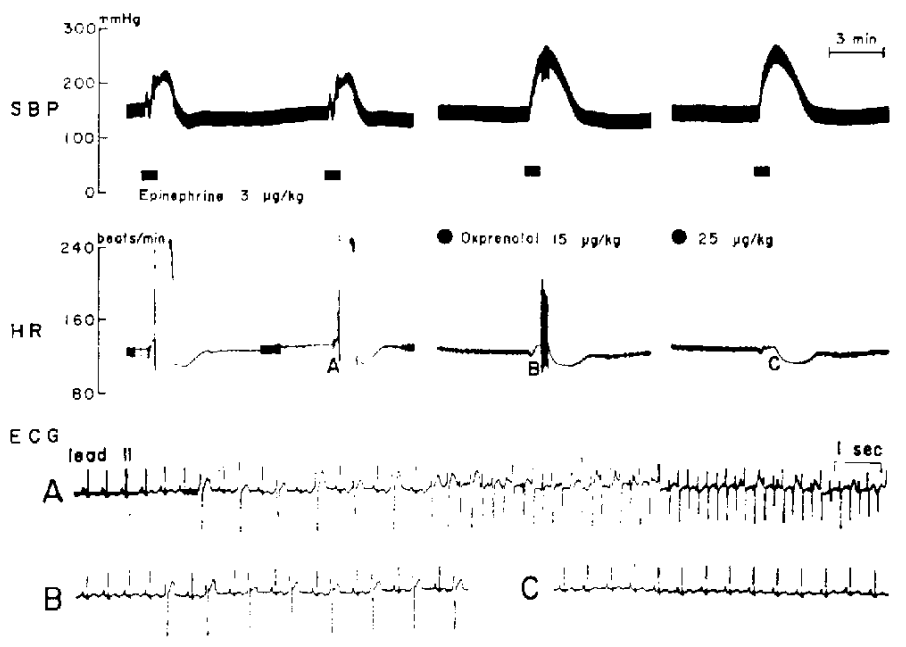

Fig. 1. Effect of oxprenolol on halothane-epinephrine arrhythmia. Epinephrine $(3 / / \mathrm{g} / \mathrm{kg})$ reproduced arrhythmia of almost the same duration and severity during the control period. After oxprenolol, arrhythmia was abolished as shown in the ECG of C. SBP: systemic blood pressure.

TABLE 1. Effects of three $\beta$-blockers on halothane-epinephrine arrhythmias, expressed by minimum antiarrhythmic ratio, i.e., $\beta$-blocker/epinephrine

\begin{tabular}{lcc}
\hline \multicolumn{1}{c}{ Drug } & $\mathrm{N}$ & $\begin{array}{c}\text { Antiarrhythmic ratio } \\
(\text { mean }+ \text { S.E.) }\end{array}$ \\
\hline Oxprenolol & 6 & $\left.14.8 \pm 4.8^{\mathrm{c}}\right)$ \\
Propranolol $\mathrm{a})$ & 7 & $3.4 \pm 1.1$ \\
${\text { Kö } 1400^{\mathrm{b})}}$ & 8 & $2.6 \pm 0.8$
\end{tabular}

a) Two experiments are added to those reported by Matsubara ct al. (4)

b) Three experiments are added to those reported by Matsubara et al. (4)

c) Statistically significant $(\mathrm{p}<0.05)$ from other two values.

paring those doses in molar concentration. In the experiment of Fig. 1, the ratio was 6.1. In earlier experiments, after determining the ratio, epinephrine was increased until arrhythmia of the same severity was reproduced, and then, the antiarrhythmic ratio was examined again. The antiarrhythmic ratios, thus obtained several times for one dog, were fairly constant.

Table 1 compares the minimum antiarrhythmic ratio of oxprenolol with those of Kö 1400 and propranolol, which were obtained by adding the present experimental results to those reported previously by us (4). The higher antiarrhythmic ratio of oxprenolol as compared to Kö 1400 and propranolol is statistically significant $(\mathrm{p}<0.05)$. The antiarrhythmic ratio of Kö 1400 was lower than that of propranolol, but the difference was not statistically significant. Although the ratio was high, the antiarrhythmic dose of oxprenolol was as low as $60 \pm 18, \mathrm{~g} / \mathrm{kg}(\mathrm{n}=6)$, a value usually thought to be a $\beta$-adrenergic blocking dose. 


\section{Coronary ligation arrhythmias}

Twenty four hours after the ligation of the anterior descending coronary artery, the average heart rate in the unanesthetized beagle dog was $184 \pm 7$ beats/min $(n=7)$ and out of this total heart rate, the sinus beats was only $18 \div 9$ beats/min, the remainder being mainly multifocal ventricular beats as shown in Fig. 2.B. Table 2 compares the incidences of successful suppression of arrhythmia by oxprenolol with those of Kö 1400 and propranolol which were reported previously by us (4). The antiarrhythmic effects resulting from a maximum dose of oxprenolol differed for each animal and were listed according to the reduced percentage of the initial arrhythmic ratio. As shown in Table 2, oxprenolol did not reduce the arrhythmic ratio more than $50 \%$ in all 6 dogs in the 24th hour, just as Kö 1400 while propranolol suppressed arrhythmia in 2 out of 5 dogs.

Fig. 3 shows the dose-response relation of the effect of oxprenolol on the total heart rate and the sinus rate. Although positive chronotropic effects of oxprenolol were found in the dog heart-lung preparation (9), this substance did not show any increase in the heart rate under the present experimental condition. In higher doses, the heart rate decreased significantly. Increase in the sinus rate was observed using $5 \mathrm{mg} / \mathrm{kg}$ of oxprenolol and the difference was significant from the control value. The dose-response patterns of Kö 1400 and propranolol were similar to that of oxprenolol. Although higher doses of oxprenolol could be given without fatality, doses higher than $5 \mathrm{mg} / \mathrm{kg}$ resulted in sedation of the dogs, and in some, tic-like movements of the head.
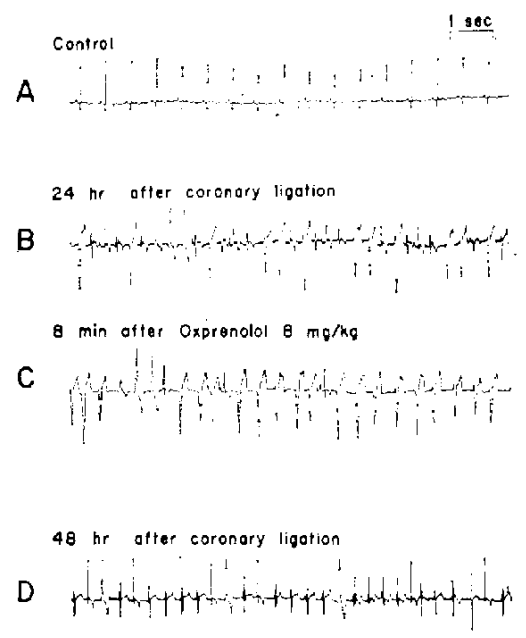

$$
\text { B min ofter Oxprenolol } 8 \mathrm{mo} / \mathrm{kg}
$$
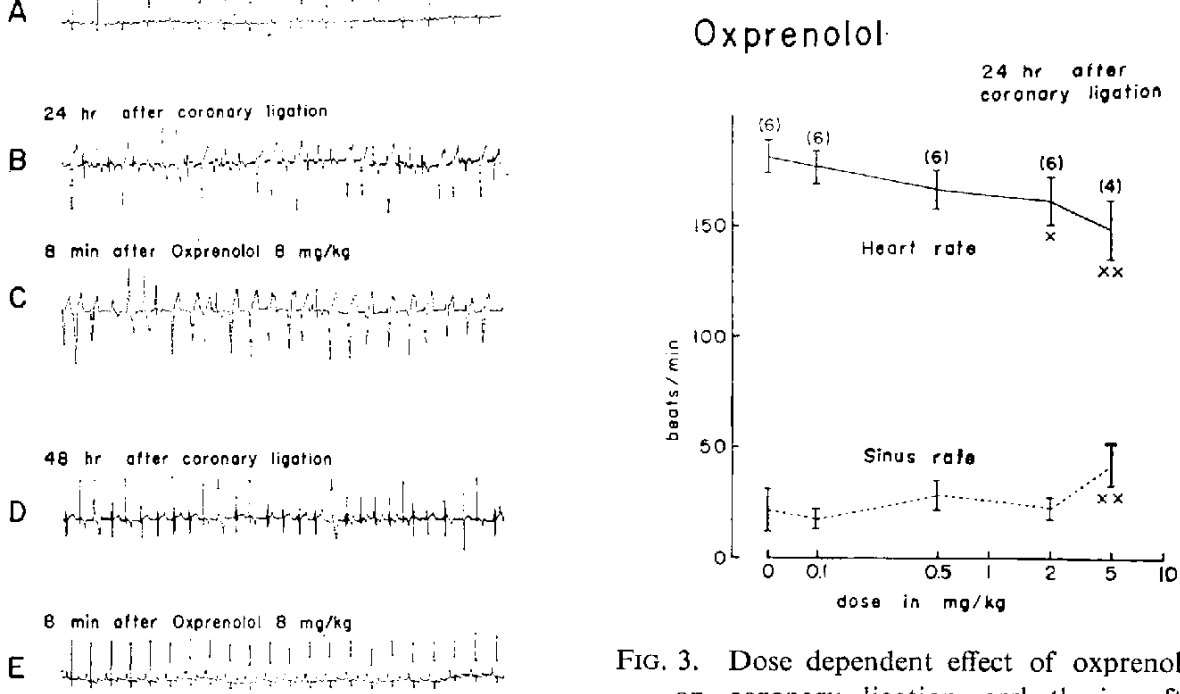

FIG. 3. Dose dependent effect of oxprenolol on coronary ligation arrhythmia after $24 \mathrm{hr}$. Numbers in parenthesis are the number of experiments. Vertical bar represents S.E. $x: p<0.05, x x: p<0.01$. P refers to comparison of the difference between control values shown at 0 and drug responses. 
On the next day, the same dogs were used to evaluate the effects of oxprenolol on arrhythmias 48 hours after coronary ligation. The dogs recovered fully from the operation and the arrbythmia decreased in severity, as shown in Fig. 2.D. The average heart rate decreased significantly to $167 \pm 9$ beats/min $(\mathrm{n}=5)$, and the sinus beats increased slightly to $23 \div 9$ beats/min $(n=-5)$. For this arrhythmia, oxprenolol showed antiarrhythmic effect. Although $10 \mathrm{mg} / \mathrm{kg}$ was necessary, oxprenolol reduced the arrhythmic ratio more than $50 \%$ in all 4 dogs, and in two of them, almost complete suppression of arrhythmia (more than $90 \%$ reduction of arrhythmic ratio) occurred as shown in Fig. 2.E. The time

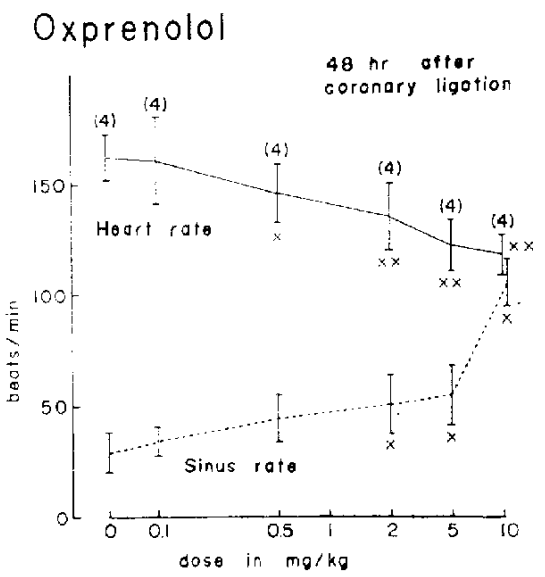

Fig. 4. Dose dependent effect of oxprenolol on coronary ligation arrhythmia after $48 \mathrm{hr}$. Numbers in parenthcsis are the number of experiments. Vertical bar represents S.E. $x: p<0.05, x x: p<0.01 . \quad P$ refers to comparison of the difference between control values shown at 0 and drug responses. to reach $50 \%$ reduction of the arrhythmic ratio was $3.3 \pm 1.1$ min and was almost the same as that of $\mathrm{Kö} 1400$ and propranolol. The duration of $50 \%$ reduction or $90 \%$ reduction of the arrhythmic ratio in 2 dogs showed that the effect was as long lasting as that of $\mathrm{Kö} 1400$ and propranolol. Antiarrhythmic effects on the 2nd post-operative day are also illustrated in the dose-response curve of Fig. 4. The sinus rate increased dose-dependently and at $10 \mathrm{mg} / \mathrm{kg}$ almost all the heart beats were sinus beais. Fifty percent decrease in the arrhythmic ratio was obtained by about $5 \mathrm{mg} / \mathrm{kg}$, which was almost the same as the values for propranolol and Kö 1400 .

\section{DISCUSSION}

Oxprenolol had an antiarrhythmic effect on halothane-epinephrine arrhythmias in low doses, however it had no effect on ventricular arrhythmias produced 24 hours after coronary ligation. Only high doses of oxprenolol showed some effect on arrhythmias 48 hours after ligation. Quantitative comparisons of the antiarrhythmic effect of oxprenolol with the other two $\beta$-blockers, propranolol and Kö 1400 (4), showed that oxprenolol had a weaker effect on the halothane-epinephrine arrhythmia than the other two, while the effect on the coronary ligation arrhythmia was as weak as the other two.

The antiarrhythmic effect of $\beta$-blockers on halothane-epinephrine arrhythmias must depend on the $\beta$-blocking activity, because the antiarrhythmic dose was in the range of the so-called $\beta$-blocking dose and the arrhythmia was induced by a $\beta$-agonist, epinephrine. The 3 -blocking activity of oxprenolol on the heart has been reported to be 1.3 and 1.8 times as potent as propranolol on the right and left atrial preparations of the guinea pig respectively (10) or 1.5 to 2 times (11) or 2 times (12) as potent as propranolol. The p-blocking 


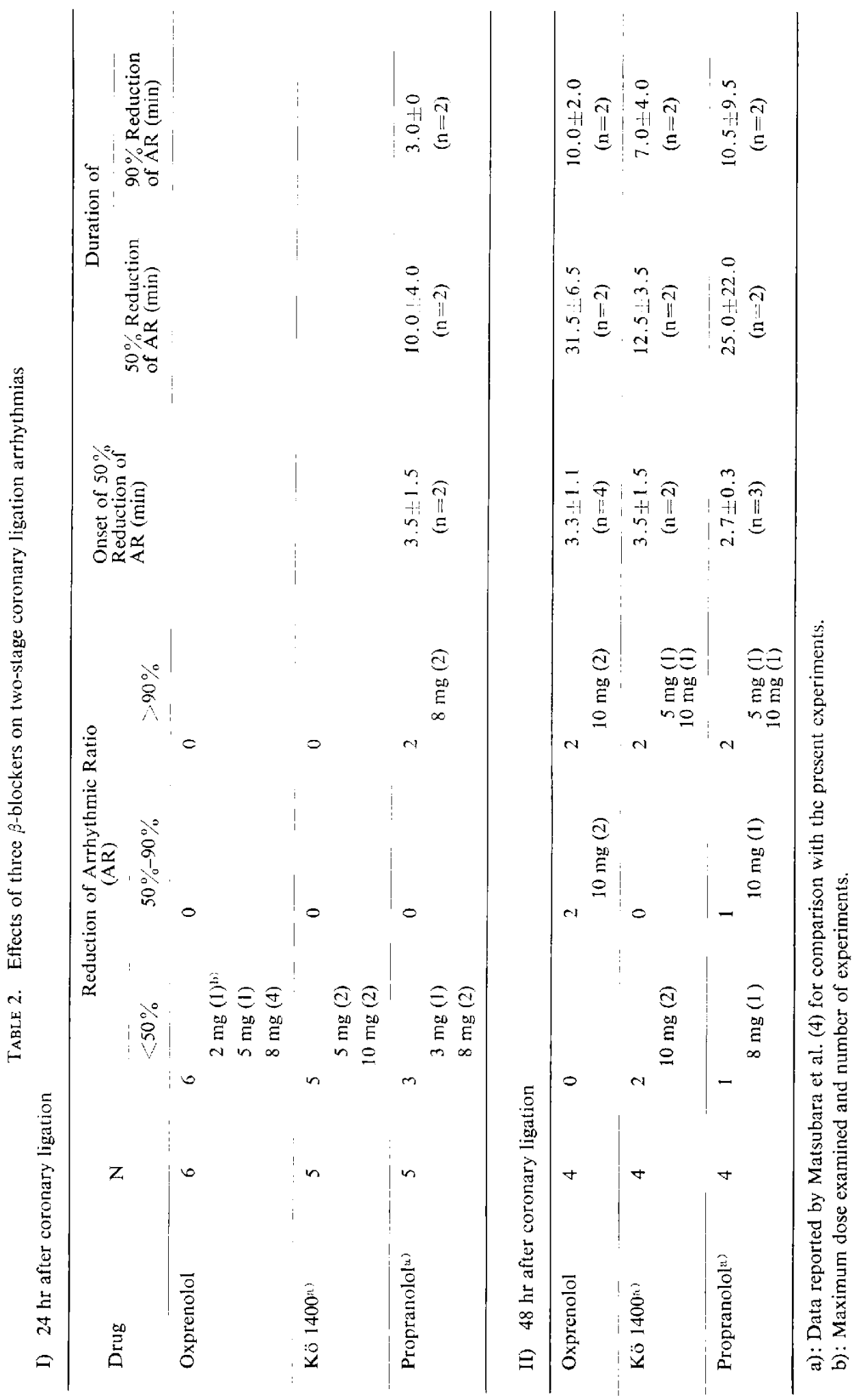


activity of $\mathrm{Kö} 1400$ is 2.3 and 3.7 times as potent as propranolol on the right and left atrial preparations of the guinea pig respectively (13). Oxprenolol was 4.45 times less potent than propranolol, while $\mathrm{Kö} 1400$ was 1.3 times as potent as propranolol in suppressing halothane-epinephrine arrhythmia in the present study. Nayler et al. (11) and Raper and Wale (14) reported almost equipotent antiarrhythmic effects of oxprenolol and propranolol on the epinephrine induced ventricular arrhythmias. Nayler et al. used only one high dose for each $\beta$-blocker, thus their method for analysis was not sufficient to obtain quantitative comparison of the $\beta$-blockers. Raper and Wales showed more quantitative data, however their analysis of antiarrhythmic potency could only differentiate sotalol (MJ 1999) from oxprenolol (Ciba $39089 \mathrm{Ba}$ ) and propranolol. The potency of $\beta$-blocking activity of sotalol is only 0.06 in their study (14) and $0.006-0.007$ in cardiac preparation of guinea pig (10) and about $0.1(12,15)$ of propranolol. Therefore their quantitative comparison of the antiarrhythmic effect of $\beta$-blockers on the epinephrine induced arrhythmia may not be precise enough to correlate with the $\beta$-blocking activity. Also their $\beta$-blocking activity of oxprenolol ( 0.6 of propranolol) is not consistent with the other reports (10-12).

The relative potency of the antiarrhythmic effect obtained from the present study (Kö 1400, 1.3: propranolol, 1: oxprenolol, 0.2) is not equal to the relative potency of the $\beta$ blocking activity of the three drugs. Kö 1400 should be more potent and oxprenolol should be as or more potent than propranolol, if the antiarrhythmic activity is due to the $\beta$-blocking activity. This discrepancy between $\beta$-blocking potency and antiarrhythmic potency of $\beta$-blockers suggests that some other effects of the $\beta$-blocker are counteracting the $\beta$-blocking activity. The effect may be the intrinsic positive chronotropic effect which is well known for oxprenolol $(9,15)$ and is also present, though weaker, in Kö $1400(4)$ and nonexistent in propranolol (12). Hashimoto and Hashimoto (5) studied the effect of the heart rate on the halothane-epinephrine arrhythmia and showed that there exists a range of heart rate which produces the arrhythmia. The prominent effect of decreasing the heart rate during epinephrine injection by $\beta$-blockers brings the heart rate far below the arrhythmic range and thus suppresses the arrhythmia. The intrinsic positive chronotropic effect may counteract the rate-decreasing effect of the $\beta$-blocker, resulting in making the effect of oxprenolol weaker than the other two and that of Kö 1400 only slightly stronger than that of propranolol. The doses producing intrinsic positive chronotropic effect of $\beta$-blocker have been reported to be almost the same as that for producing $\beta$-blockade (15). This also supports our conclusion.

The effects of oxprenolol and the other two $\beta$-blockers on the coronary ligation arrhythmia were almost negligible as compared to those of $\mathrm{CH}-200$, lidocaine and procainamide using the same quantitative methods for comparison (8). Some cases in which $\beta$-blockers were effective required a high dose which far exceeds $\beta$-blocking doses. This indicated that the mechanism of the antiarrhythmic effect is probably due to the local anesthetic, or membrane stabilizing effect of the $\beta$-blockers $(3,16)$. The three $\beta$-blockers have not been compared in their local anesthetic activity simultaneously, but from the studies of Marmo et al. (17) and Raper and Wale (14), oxprenolol and Kö 1400 are 2 to 5 times less potent in 
local anesthetic activity than propranolol. This may explain why the use of propranolol resulted in somewhat stronger antiarrhythmic activity in the coronary ligation arrhythmia than oxprenolol and $K \ddot{0} 1400$, but the difference in the antiarrhythmic effects on the coronary ligation arrhythmia among the three was not so significant as that in the local anesthetic activity. Becausc of the lack of prominent antiarrhythmic effect and quantitative differences among the three, 3 -blockers, no clectrophysiological experiments using isolated canine cardiac preparations were performed. Previously we studied the electrophysiological effects of antiarrhythmic drugs and concluded that increase in the effective refractory period is responsible for their effects on the coronary ligation arrhythmia and also showed that the dccrease in the maximum rate of rise of the action potential (often used as a measure of the membrane stabilizing effect) occurs independently of the change in the refractory period (8). It may be speculated that the effect of the three $\beta$-blockers to increase the refractory period of the ventricular muscle is weak and no quantitative difference in the effect exists among the three $\beta$-blockers. Inui and Imamura reported that the $\beta$-blockers, propranolol and bufetolol, had no effect on the refractory periud of the canine ventricular muscle even when high doses were used. (18).

As for clinical implication, the present study indicates that the use of oxprenolol and other $\beta$-blockers for suppressing ventricular arrhythmias in myocardial infarction may be questionable, bccause the effective dose of $\beta$-blockers must be too high for patients with reduced cardiac function. However as reported by Green et al., low doses of $\beta$-blockers must be effective in myocardial infarction when increased sympathetic tone modifies the clinical picture (19).

Acknowledgements: The authors thank Ciba-Geigy, Japan for kindly providing oxprenolol. They also thank Mr. H. Sakurai and Mr. A. Mitomi for their teclnical assistatnee and Miss $Y$. Kato for preparing the manuseript.

\section{REFERENCES}

1) SEhiYa, A. And Vaughan Willams, F.M.: A comparison of the antifibrillatory actions and effects on intracellular cardiac potentials of pronethatol, disopyramide and quinidine. Brit. J. Pharmacol. 21, 473-481 (1963)

2) LuCcHEsr, B.R.: The action of ncthalide upon cxperimentally induced cardiac arrhythmias. J. Bharmacol cxp. Ther. 145, 286-291 (1964)

3) KaLMANN, A.J. AND ARAM NDiA, P.: Prevention of ventricular fibrillation induced by coronary ligation. J. Phamicol. exp. Ther. 164, 326-332(1968)

4) Maisumara, I., Hashimoro, K., Kaisio, Y., Tsukada, T., Matsuda, H., Nabata, H, and IMAI, S. : Antiarrhythmic elfects of dl-1-(tert. butylamino)-3-[(2-propinyloxy)phenoxy]2-propanol hydrochloride ( $\mathrm{K}: \mathrm{i}$ 1400-Cl), a new adrenergic $\beta$-blocking agent. Folia phamacul. japon. 72, 557-571 (1976) (Abs. in English)

5) Hashivoto, K. Avis HAstmoto, K.: The mechanism of sensitization of the ventricle to epinephrine by halothane. $1 \mathrm{~m}$. Howt $J .83,652 \cdot 658$ (1972)

6) HARris, A.S.: Delayed development of ventricular ectopic rhythms following experimental coronary occlusion. Circulation 1, 1318-1328 (1950)

7) SHand, D.G.: Pharmacokinetic properties of the $\beta$-adrenergic receptor blocking drugs. Drugs 7, 39-47 (1974)

8) Hashimote, K., Tsukada, T., Matsuda, H. A.vd Imai, S.: Antiarrhythmic and electrophysiologrical eticcls of (H-200. Europ. J. Pharmacol. 45, 185194 (1977) 
9) TAKedA, K., IIzUKa, H. AND Imai, S.: Cardiac actions of oxprenolol as studied in dog heartlung preparations. Arzneim.-Forsch. 23, 1446-1450 (1973)

10) Horil, D., Kawada, T., TAKLda, K. Axd Imal, S.: Comparison of $\beta$-adrenergic blocking aclivities of propranolol, isopropylmethoxamine, sotalol, practolol, alprenolol, pindolol, oxprenolol and D-32 in the atria and trachea of the guinea-pig. Arzheim.Forsch. 24, 1275-1277 (1974)

11) Naylek, W.G., Chan, J. ANd LOWE, T.E.: Beta adrenergic antagonists, including ICI 50172 , and the control of cardiac arrhythmias. Med.J. Aust. 1, 1128-1130(1968)

12) FitzGlkald, J.D.: Perspectives in adrenergic beta-receptor blockade. Clin. Pharmacol. Ther. 10, 292-306 (1969)

13) Imzuka, H., Nakagawa, Y., Matsubara, I., Imai, S. nnd Yanagita, T.: Drug elfects on blood pressure and heart rate in unanesthetized animals. (1) Effects of $\beta$-blocking agents. Folia pharmacol. japon. 73, $401-409$ (1977) (Abs. in Eng/ish)

14) RaPlr, C. AND Wale, J.: Propranolol, MJ 1999 and Ciba $39089 \mathrm{Ba}$ in ouabain and adrenaline induced cardiac arrhythmias. Europ. J. Pharmacol. 4, 1-12 (1968)

15) BarretT, A.M. AND CARTFr, J.: Comparative chronotropic activity of $\beta$-adrenoceptive antagonists. Brit. J. Pharmacol. 40, 373-381 (1970)

16) SCHMid, J.R. AND HanNA, C.: A comparison of the antiarrhythmic actions of two new synthetic compounds, iproveratril and MJ 1999, with quinidine and pronethalol. J. Pharmacol. exp. Ther. 156, 331-338 (1967)

17) Marmo, E., Caplti, A.P. ANd SaIN, R.K.: New N-isopropyl and N-tert.-butyl-phenoxypropanolaminic derivalives having $\beta$-adrenolytic, anti-arrhythmic and local anaesthetic activity. Arzneim.-Forsch. 22, 1109-1117 (1972)

18) InUi, J. AND Imamura, H.: Effects of bufetolol and propranolol on active and passive membrane properties of dog papillary muscle. Japan. J. Pharmacol. 26, 639-647 (1976)

19) GREEX, K.G. (trial coordinator), and 76 other authors.: Improvement in prognosis of myocardial infaretion by long-term beta-adrenoreceptor blockade using practolol. A multicentre international study. Brit. med. J. 3, 735-740 (1975) 